\title{
A repetição na linguagem do sujeito MM: uma discussão à luz da Neurolinguística Discursiva
}

\section{Language repetition of patient MM: a discussion in the light of Discursive Neurolinguistics}

\author{
Nirvana Ferraz Santos Sampaio* \\ nirvanafs@terra.com.br \\ Universidade Estadual do Sudoeste da Bahia \\ Mariza dos Anjos Lacerda* \\ marizza.anjos@gmail.com \\ Universidade Estadual do Sudoeste da Bahia
}

\begin{abstract}
RESUMO: Neste artigo, apresentamos resultados a respeito da repetição na linguagem oral do sujeito MM que apresenta a palilalia como alteração linguística. Descrevemos e analisamos a repetição na fala desse sujeito. Para tanto, utilizamos os estudos da Neurolinguística Discursiva (ND) aliados aos estudos referentes à repetição presentes na Linguística. Os resultados apontam que as repetições estão além de um monitoramento da linguagem oral estabelecendo um planejamento visto e que se apresentam como uma forma de manutenção de $\mathrm{MM}$ na interação por meio de atividades epilinguísitcas.
\end{abstract}

PALAVRAS-CHAVE: Neurolinguística Discursiva. Repetição. Palilalia.

ABSTRACT: In this paper, we present results regarding oral language repetition of the subject MM that shows palilalia as linguistic change. We describe and analyze this subject's spoken language. To do so, we use Discursive Neurolinguistics (DN) studies along with Linguistic studies that focus on repetition. The results indicate that the repetitions are beyond the monitoring of oral language that establishes a planning activity and that they are presented as a form maintenance of MM in the interaction through epilinguistic activities.

KEYWORDS: Discursive Neurolinguistics. Repetition. Palilalia.

\footnotetext{
" Doutora em Linguística pela Universidade Estadual de Campinas; professora titular de Linguística na Universidade Estadual do Sudoeste da Bahia-UESB; professora do Programa de Pós-Graduação em Linguística da UESB; pesquisadora do Grupo de Pesquisa em Estudos da Língua(gem) (CNPq/UESB) e Líder do Grupo de Pesquisa e Estudo em Neurolinguística (CNPq/UESB).

Mestranda do Programa de Pós-Graduação em Linguística (PPGLin), UESB.
} 


\section{Introdução}

Este artigo é fruto de um estudo de caso longitudinal com a linguagem do sujeito $\mathrm{MM}^{1}$ que, em meados do primeiro semestre de 2011, aos 45 anos, apresentou, segundo relatório médico, uma cefaleia intensa, ocasionando uma ruptura de um aneurisma, deixando, assim, alterações linguísticas em sua linguagem verbal.

Dito isso, e reconhecendo que a linguagem é um meio para que o homem possa interagir com o mundo à sua volta, a força motriz que rege este trabalho consiste em investigar as repetições como alterações linguísticas apresentadas pelo sujeito em questão a fim de verificar as dificuldades e possibilidades que ele evidencia na sua linguagem oral/falada. Para tanto, o trabalho está ancorado na Neurolinguística Discursiva (doravante ND) e na teoria histórico-cultural.

Os questionamentos que direcionam a nossa pesquisa são: i) o que se evidencia de distinto da linguagem típica na repetição realizada pelo sujeito MM?; ii) Qual intervenção pode ser feita a partir da Neuroliguística Discursiva? Consideramos que a repetição apresentada na linguagem de $M M$ se configura em um distanciamento da linguagem típica, visto que não se trata de repetições que ocorrem tipicamente na oralidade. Entretanto, configura-se também por caminhos diferentes que funcionam como processo alternativo para a manutenção de MM nas suas interações, a partir da intervenção do outro/pesquisador como mediador na reconstrução da linguagem.

A repetição é um fenômeno linguístico muito utilizado tanto em linguagem típica quanto atípica. Para abordar esse fenômeno, o presente trabalho está organizado da seguinte forma: na primeira seção, mostramos como a linguagem e o discurso são concebidos pela ND; na segunda seção, discutimos a repetição na oralidade tanto em linguagem normal quanto em contexto patológicos; na terceira seção, apresentamos a metodologia que direcionou esta pesquisa; na quarta seção, analisamos os dados fazendo ponte com a teoria estudada e os dados-achados; e por fim, temos a seção dedicada às considerações finais, seguida das referências.

\footnotetext{
${ }^{1}$ MM é o sujeito informante deste trabalho, que é parte integrante do projeto que compõe a dissertação de mestrado de uma das autoras. O projeto foi aprovado pelo comitê de ética da UESB com o número de registro: 51259115.3.0000.0055. O sujeito assinou o Termo de Consentimento Livre e Esclarecido.
} 


\section{Neurolinguística Discursiva, linguagem e discurso}

Ao propormos investigar a repetição na linguagem de $\mathrm{MM}$, faz-se necessário compreender, primeiramente, como a linguagem e o discurso são vistos em contextos patológicos à luz da Neurolinguística Discursiva. Nesta seção, abordaremos, de forma sucinta, questões pertinentes à Neurolinguística Discursiva, tais como a linguagem e o discurso. Antes, trataremos um pouco sobre a prioridade da Neurolinguística.

A Neurolinguística é um campo recente da Linguística. No Brasil, a Neurolinguística aparece como disciplina e área de pesquisa a partir da década de 1980 na Universidade Estadual de Campinas, UNICAMP.

Sobre a Neurolinguística, Morato (2010) recorda Caplan (1987) ao dizer que:

[a] Neurolinguística é o estudo das relações entre cérebro e linguagem, com enfoque no campo das patologias cerebrais cuja investigação relaciona determinadas estruturas do cérebro com distúrbios ou aspectos específicos da linguagem (MORATO, 2010, p.143-144).

Lebrun (1983), em conformidade com o que foi dito, afirma que a neurolinguística se interessa pelo indivíduo que, tendo uma afecção do seu sistema nervoso central, apresenta dificuldades de adquirir ou utilizar adequadamente um código verbal. Para tanto, ao estudar os problemas adquiridos e de desenvolvimento da linguagem advindas de uma lesão, afecção ou disfunção do sistema nervoso central, a Neurolinguística é uma disciplina que adota metodologia e princípios próprios.

Entretanto, os estudos pautados na Neurolinguística tradicional visam a estudos metalinguísticos que enxergam a língua como um sistema fechado. Em oposição a essa Neurolinguística tradicional surge uma Neurolinguística discursivamente orientada postulada por Coudry (1988) após seu doutoramento em Bruxelas. Daí o nome Neurolinguística Discursiva (doravante, abreviada como ND).

Pensar a linguagem à luz da ND requer uma reflexão sobre a linguagem e o discurso em contextos patológicos. Segundo Coudry (2001), a linguagem é vista num contínuo processo que se resulta de um trabalho coletivo, histórico e cultural 
que se manifesta num conjunto de recursos próprios de cada língua. Nesse sentido, compreendemos a linguagem como o lugar de interação humana.

$\mathrm{Na}$ ND, Coudry (2001) adota a concepção de linguagem postulada por Franchi (1977). Nas palavras do autor:

\begin{abstract}
Não há nada imanente na linguagem, salvo sua força criadora e constitutiva, embora certos "cortes" metodológicos e restrições possam mostrar um quadro estável e constituído. Não há nada universal, salvo o processo - a forma, a estrutura dessa atividade. $A$ linguagem, pois, não é um dado ou resultado; mas um trabalho que "dá forma" ao conteúdo variável de nossas experiências, trabalho de construção, de retificação do "vivido", que ao mesmo tempo constitui um sistema simbólico mediante o qual se opera sobre a realidade como um sistema de referências em que aquele se torna significativo. Um trabalho coletivo em que cada um se identifica como os outros e a eles se contrapõe, seja assumindo a história e a presença, seja exercendo suas opções solidárias (FRANCHI, 1977, p. 31-32) (ênfase nossa).
\end{abstract}

Nesse sentido, conforme Coudry (2001), e, nessa concepção de linguagem, a língua é resultante de um trabalho social de experiências que se reproduzem e se perpetuam. A autora adverte, ainda, que o que deriva do social não é a língua enquanto sistema, mas, sim, as regras sociais advindas do jogo da linguagem dadas pela prática com a linguagem. Dessa maneira, compreendemos que a ND adota a concepção de linguagem como uma atividade constitutiva própria da interação humana.

Em distúrbios de linguagem e do ponto de vista linguístico, a concepção de linguagem constitutiva permite ao investigador interpretar as falhas e "erros" como uma possibilidade de reconhecer os caminhos que o sujeito trilha na construção de seu discurso. Assim, permite-se que o sujeito com patologia possa reconstruir, frente à face interpessoal, o jogo da linguagem "em que encontrará, senão o sistema da língua, os recursos alternativos que lhe permitam desempenhar seus múltiplos papéis" (COUDRY, 2001, p. 57).

As atividades com a linguagem na ND parte do princípio de que o sujeito com uma lesão no sistema nervoso central ainda seja capaz de operar com e pela linguagem podendo fazer uso de elementos alternativos ou exercendo a força criadora da linguagem. 
Uma das atividades linguísticas mais utilizadas na ND é a epilinguística. Coudry (2001) define as atividades epilinguísticas como aquelas que o sujeito opera com e sobre a linguagem, explorando os recursos da sua própria linguagem e fazendo uso de novos elementos linguísticos para se enunciar. Quando esses feitos novos são elaborados, temos uma hipótese de estruturação na sua forma e uso significativo da linguagem por esse sujeito.

Para a autora:

a atividade epilinguística recobre a operações diversas sobre a linguagem, como transformar, segmentar, reordenar, reiterar, inserir, fazer escolhas e, mesmo, pensar sobre a linguagem e os processos de construção em que está envolvido (COUDRY, 2001, p. 16).

Dito isso, vemos que a linguagem na patologia, com base na teoria da ND, permite ao sujeito uma autonomia de linguagem própria de quem a usa, pois todo falante natural e sem alterações linguísticas na linguagem recorre a uma reinteração ou uma inserção, dentre outros mecanismos, para criar significação ao que está sendo dito. Todos recorremos à linguagem para designar as nossas intensões conforme a nossa vontade. Em casos de patologias de linguagem essa atividade não é diferente. A diferença está na postura que o outro se apoia diante da linguagem e das possibilidades que se oferece ao sujeito com patologia de linguagem. A essa perspectiva discursiva, Coudry (2010) sublinha que a ND toma como ponto de partida a interlocução e tudo que a ela diz respeito.

No discurso, Coudry (2001) busca suporte em Osakabe (1979), que, a partir dos estudos de Benveniste (1970), cria uma linha de raciocínio para constituir o seu conceito. Para este autor, o discurso se caracteriza pelo grau de participação do eu/tu, da situação e da pragmaticidade. Segundo o autor, o discurso é necessariamente significativo ao passo que a sua existência está diretamente ligada a um processo pelo qual eu e tu se aproximam pelo significado. A semanticidade se garante pela situacionalidade. Dessa maneira, vemos que dentro do discurso patológico os fatores pragmáticos também estão presentes, pois envolve o processo da relação que se estabelece entre as duas pessoas (eu e tu), as pessoas da situação, e entre as condições dêiticas de tempo e lugar.

O discurso entra no quadro das construções simbólicas ao expressar as condições significativas que os participantes trazem à tona à interlocução ao passo 
que um age sobre o outro e sobre a própria situação. Segundo Coudry (2001), "o discurso, pois, 'constitui' a experiência” (COUDRY, 2001, p.64).

Em contextos patológicos, como propõe os estudos neurolinguísticos discursivos, por meio da interlocução, o discurso vai além do estudo "da forma" postulada por Benveniste (1970), pois o seu objetivo também é, para o investigador, detectar os processos discursivos que foram ou não afetados além dos processos discursivos alternativos que o sujeito com uma disfunção passa a elaborar, geralmente, relacionado com a gravidade e a natureza da dificuldade de linguagem.

Conforme Coudry (2001), voltando à linguagem indeterminada que norteia a ND,

as expressões linguísticas não carregam em si todos os elementos necessários a sua interpretação. É pois enquanto discurso, envolvendo todos os demais fatores contextuais e intersubjetivos, que a significação é possível. Mesmo nas linguagens formais, que por uma exigência de explicitude se constroem de um modo determinado, completo e não ambíguo, há um discurso prévio geralmente posto entre parêntesis que garante essa determinação (COUDRY, 2001, p. 65).

Assim, compreendemos que as relações no discurso não são dadas previamente, podendo não haver traço comum entre os participantes. É por isso que, quando as relações se constituem no discurso, essa constituição se dá por uma negociação permanente. Essa negociação pode vir explicita ou implícita. Para Coudry (2001):

A negociação é um processo pelo qual os interlocutores procuram fazer coincidir as imagens que cada um faz do outro, comparam entre si os compromissos com a verdade e crenças que possuem sobre os processos envolvidos na conversação e testam a eficácia dos recursos expressivos de que se servem, escolhem a "clave" e o registro, enfim o estilo da sua fala (COUDRY, 2001, p. 65).

Ressaltamos que nos estudos que envolvem a neurolinguística tradicional a negociação é apartada por se servir de testes metalinguísticos sobre os fatos da linguagem. Não se trata de discurso e nem se constituem relações de interlocução. Entretanto, consideramos que tanto a linguagem quanto o discurso se constituem por meio da negociação dada na relação dos envolvidos nesse processo. Ambos, linguagem e discurso, não são dados como algo determinado, mas por uma construção contínua que leva em conta as particularidades históricas, sociais e culturais de cada um envolvido nesse processo. 
Tendo em vista a apresentação da discussão sobre a linguagem e o discurso, à luz da neurolinguísitca discursiva, apresentados nessa seção, ratificamos a sua importância para este trabalho. Adiante, discutiremos sobre um fenômeno muito comum na linguagem, a repetição. A repetição será estudada com base na linguagem constitutiva que permeia o ser humano sob os postulados da neurolinguística discursiva ao investigar a fala de um sujeito que teve o seu sistema nervoso central afetado após um aneurisma, deixando como sequela, na sua fala, a palilalia.

\section{Aspectos teóricos da repetição na oralidade}

A repetição é um fenômeno muito presente na língua falada. $O$ alto índice de repetições na fala deu espaço a vários estudos sobre esse fenômeno. Como referência figuram os nomes de Ramos (1983), Bessa Neto (1991), Marcuschi (1992, 2006) e Lagrotta (2001).

Numa perspectiva linguística, a repetição vem sendo explicada a partir de contextos textuais interativos. A repetição é estudada e apresentada como parte integrante do discurso, sendo esse, mais especificamente, o texto oral. Consideramos texto oral qualquer texto que seja vocalizado, como por exemplo, diálogos, provérbios, músicas, marchinhas, etc.

Ramos (1983) fez um estudo pioneiro sobre as repetições na linguagem oral a partir de contextos textuais interativos ao aprofundar seus conhecimentos sobre as hipóteses para uma taxonomia das repetições no texto falado e define a repetição como "a ocorrência do mesmo conjunto de palavras, duas ou mais vezes, recebendo a mesma interpretação semântica" (RAMOS, 1983, p.52). Em seu estudo, Ramos (1983) observou que há dois tipos de repetição: i) as que contribuem para facilitar a tarefa do ouvinte e ii) as que não contribuem para esse fim. Segundo a mesma autora, a repetição tem uma função comunicativa cujo propósito é tornar o enunciado mais acessível, ou seja, mais fácil para o ouvinte. Adverte, ainda, que a presença da repetição não está relacionada a nenhuma língua específica, mas, sim, ao processo de interação.

Outra autora que se interessou pelos estudos da repetição foi Bessa Neto (1991). Em seu estudo, ela analisou de maneira sistemática as repetições faladas e escritas, atuando na repetição lexical, analisando textos orais e escritos. De acordo 
com esta autora (1991), as repetições foram evidentes em casos que aparecem para criar significação, para atender as especificidades de sua produção, para conectar uma a uma, para conectar diferentes segmentos e para indicar o tema que se trata sendo mais frequente nos textos orais do que em textos escritos. Bessa Neto (1991) ressalta que algumas funções são mais frequentes que outras, sendo que certas funções são exercidas por um tipo de repetição e não por outra.

Em 1992, Marcuschi, num estudo minucioso sobre o aspecto da repetição, mostra que o fenômeno da repetição na linguagem é característica da língua falada. De acordo com o linguista, "a repetição é, certamente, um dos mecanismos mais salientes na produção, condução e compreensão do texto dialogado" (MARCUSCHI, 1992, p.1). Marcuschi justifica essa afirmação ao mencionar que a eliminação das repetições em alguns casos pode acarretar textos incompreensíveis e, além disso, diminui o entrosamento interpessoal. Marcuschi (1992) define a repetição como a "produção de segmentos discursivos idênticos ou semelhantes duas ou mais vezes no âmbito de um mesmo evento comunicativo" (MARCUSCHI, 1991, p. 31). Para essa definição, o autor teve como base empírica a conversação. Entretanto, a repetição não pode ser vista com um mero ato metalinguístico, pois ela expressa algo novo. Portanto "repetir as mesmas palavras num mesmo evento comunicativo não equivale a dizer a mesma coisa" (MARCUSCHI, 1992, p. 32).

Dito isso, podemos dizer que a repetição é, assim como a hesitação, a correção, a paráfrase e os marcadores conversacionais, uma característica da construção textual natural da fala. Outro aspecto importante apresentado pelo autor em relação à língua falada e às repetições é que, na fala, as repetições apresentamse com características típicas de um planejamento ad hoc. Para Marcuschi (2006), na fala, as repetições apresentam-se com características de um planejamento on line, ou seja, o discurso se constrói no decorrer da interação, traçando características de um texto não planejado. Nesse caso, nada se apaga, fazendo parte do processo formulativo. A presença da repetição no texto falado é alta - ao contrário da escrita, em que, com a revisão textual, ocorrem apagamentos sucessivos, evitando, assim, as redundâncias e obtendo uma versão final. A marca da repetição na fala resulta um texto menos denso e com maior envolvimento interpessoal, tornando a repetição essencial nos processos de textualização na língua falada. 
Devido à grande presença das repetições na linguagem oral, Marcuschi (1992) adverte que a presença da repetição natural do falante não se trata de um problema de acesso limitado ao acervo lexical disponível na memória, mas de marcação rítmica dentre outras coisas. Para Marcuschi (1992), é comum um falante se repetir com certa frequência ou repetir o outro, mostrando que há uma reciprocidade entre os interlocutores. Ressalta ainda que definir o que é ou não uma repetição não é tarefa fácil devido à grande quantidade de formas apresentadas na língua falada.

Vemos, dessa maneira, que a repetição é um item linguístico muito comum na oralidade como expomos acima e que a sua presença na linguagem falada não ocorre de maneira aleatória, mas por uma necessidade de favorecer o discurso, deixando-o mais acessível para o ouvinte. Adiante, abordaremos a repetição em contextos patológicos de linguagem.

\subsection{A repetição em patologias de linguagem}

A repetição é um fenômeno linguístico que ocorre tanto na linguagem de pessoas que não passaram por episódio neurológico que não afetou a linguagem quanto em pessoas nessas condições. Algumas repetições, nesse contexto, são automatizadas $^{2}$, ou seja, a sua produção ocorre independente da interação do sujeito, sendo, portanto, involuntário e sem carga semântica.

Em patologias de linguagem, as repetições provêm de naturezas diferentes e com características neurolinguísticas que se associam às dificuldades de selecionar palavras, aos problemas de processamento e de ordem mnésica ${ }^{3}$ ou fonoarticulatória. São vários os fenômenos linguísticos que se constituem de elementos repetidos, como por exemplo, a perseveração ${ }^{4}$, a estereotipia ${ }^{5}$, o

\footnotetext{
${ }^{2}$ Segundo Janaísa MartinsViscardi (2005), em sua dissertação de mestrado, o automatismo é definido como a emissão repetitiva do mesmo segmento linguístico (podendo ser uma sílaba, uma palavra ou uma sentença), a sua ocorrência é tida como não contextualizada, de caráter automático e constante na fala.

${ }^{3}$ Prática que facilita as operações da memória.

${ }^{4}$ Neisser (1895) define perseveração como repetição interativa ou a continuação de uma resposta anterior após a mudança de turno.

${ }^{5}$ Lebrum (1983) define estereotipia como uma fixação de uma fórmula invariável de atitudes, gestos, atos ou expressões verbais prolongadas e repetidas incessantemente.
} 
circunlóquio $^{6}$, a ecolalia ${ }^{7}$ e a palilalia $^{8}$ são alguns exemplos que marcam essa alteração linguística.

A repetição na linguagem é estudada desde Aristóteles (século IV a.C.). Nessa época o fenômeno repetição era associado à perseveração que era vista como uma função de temperamento e das emoções que afetava o sujeito.

A repetição em contextos patológicos está relacionada à perseveração que, segundo Neisser (1895), é uma repetição interativa ou a continuação de uma resposta anterior após a mudança de turno. Entretanto, nem todas as repetições em contextos patológicos devem ser consideradas como uma perseveração.

Lima (2010) traça historicamente estudos sobre a relação da repetição com a perseveração. Segundo a autora, a concepção de perseveração, na primeira metade do século passado, estava relacionada a processos que implicavam as questões sensoriais concebidas como pensamento, atividade psicomotora e motricidade. Dessa maneira, a perseveração era interpretada como uma alteração no Sistema Nervoso que ocorria em determinados sujeitos, afetando assim as atividades desenvolvidas pelo sujeito como um todo.

Para Allison (1966 apud LIMA, 2010), a questão fundamental na ocorrência da perseveração é que ela se manifesta tanto em pessoas normais quanto em pessoas que tiveram um comprometimento cerebral. Nesse último caso, a repetição se dá em lesões focais. Lima (2010) menciona que, para Helmick e Berg (1976), a perseveração também se manifesta em pacientes com distúrbios neurológicos de fala e de linguagem. Para esses autores, a perseveração é a continuação de uma resposta iniciada ou a recorrência à resposta prévia e a classificam em dois tipos: repetitiva e contínua. Na primeira, a repetição se manifesta após a interrupção por algum evento; já na segunda, baseia-se nas respostas dadas sem nenhuma interferência e que sofre repetição.

Em sua tese de doutorado, Lima (2010), com base em Geraldi (1991), propôs que a perseveração fosse estudada em contexto onde a linguagem estivesse em contexto espontâneo e não em testes padrões, como tem sido, para isso baseou-se em uma visão interacionista do fenômeno, privilegiando a interlocução com um espaço produtor de linguagem e constitutivo do sujeito.

\footnotetext{
${ }^{6} \mathrm{O}$ cincunlóquio é o uso excessivo de uma palavra para exprimir uma ideia.

${ }^{7}$ Saad e Godfeld (2009) consideram como repetição de itens lexicais de turno anterior.

${ }^{8}$ Gritchley (1927) se refere à palilalia como as repetições de itens lexicais de turno anterior proferidos pelo próprio orador.
} 
Dessa maneira, a perseveração é contemplada, na interlocução, pela atitude do falante que é marcada pelo contexto intersubjetivo e social de produção de linguagem. Nesse sentido, a autora assinala que a questão da perseveração pode ser vista como uma resposta constitutiva e integrante da atividade da linguagem.

Dentro das patologias de linguagem, um estudo pioneiro sobre as repetições na linguagem com alterações foi desenvolvido por Tagliaferre (2008), que, baseando-se nos trabalhos de Marcuschi (1992), versa sobre repetições nas afasias. Para seu estudo, a autora analisa as repetições na produção oral de dois sujeitos com afasia, um fluente e o outro não fluente.

Segundo a mesma autora, a repetição na linguagem de afásicos não é somente uma estratégia comunicativa utilizada para se fazer compreender ou ser compreendido, mas também se trata de um mecanismo muito mais complexo que contribui sobremaneira para o processamento do texto falado. Dessa maneira, a repetição age atuando como fator de interação e de sócio-cognição.

De acordo com Tagliaferre (2008), os estudos mais tradicionais na afasiologia enfatizam que os sujeitos afásicos apresentariam dificuldades em lidar com situações linguísticas mais complexas, ou seja, com os aspectos funcionais da linguagem. Entretanto, em seu estudo, foi observado que, em muitas situações interacionais, os sujeitos conseguiram lidar com as dificuldades linguísticas de maneira criativa ao se servirem de estratégias que contemplam as formas e funções da repetição dispostas na/para a conversação.

No decorrer da interação, segundo a autora, os sujeitos afásicos se valem das atividades epilinguísticas. Essa recorrência se dá devido ao valor reconstrutivo na busca de alternativas para resolverem as dificuldades encontradas durante a conversação. A atividade epilinguística "se explicita ao examinador nos silêncios, nas parafasias, nas contaminações, autocorreções, e mesmo quando se expressa sua tensão e insegurança" (COUDRY, 2001, p.16). A atividade epilinguística permite aos afásicos operar com e sobre a linguagem. Nesse sentido, as repetições atuam na fala dos afásicos como uma maneira de cobrir lapsos ou para preencher lacunas que geralmente ocorre na sua fala, favorecendo uma atividade constitutiva.

Como o trabalho foi baseado em Marcuschi (1992), a autora diz que a maior semelhança entre as repetições produzidas entre afásicos e não afásicos se dá nas repetições próximas, que aparecem como características do texto falado, diferenciando apenas que entre não afásicos a repetição é produzida nas 
autorrepetições. Talvez essa diferença seja em virtude do corpus textuais-interativos apresentadas em seu trabalho.

Poderíamos, assim, dizer que a repetição tem naturezas diferentes e que, embora seja um fenômeno que marca uma fala estereotipada, a sua ocorrência não é tão limitada, pois se trata de um fenômeno muito recorrente na linguagem oral que envolve a colaboração dos participantes do diálogo.

\subsection{Palilalia}

A palilalia, como mencionado anteriormente, é uma alteração de linguagem pouco estudada e que consiste na repetição de duas ou mais sílabas, palavras ou frases num mesmo evento comunicativo proferido pela mesma pessoa. Essa alteração de linguagem é uma sequela que caracteriza outra patologia de linguagem, a saber: a disártria.

Esse fenômeno ocorre a partir de transtornos de linguagem e é uma sequela dos transtornos motores decorrentes de lesão cerebral. A palilalia é uma alteração linguística menos frequente e foi descrita por Souques (1908), embora Brissaud a tenha definido como uma autoecholalia pelo parentesco com a ecolalia. Critchley (1927) descreveu a palilalia como sendo uma repetição involuntária, espontânea e consciente de uma mesma sílaba, palavra ou frase podendo ser repetida uma ou mais vezes (LEMOS, 1992, p. 37).

De acordo com a literatura internacional, a palilalia é um transtorno de linguagem que está associada à doença de Parkinson, síndrome de Tourrette e acidentes vasculares cerebrais. Landi et. al. (2012) afirmam que a palilalia tem sido descrita em várias desordens neurológicas, tais como: acidentes cerebrais, doenças degenerativas e síndromes de tiques.

Cho et al. (2009) postulam que a palilalia é uma reinteração espontânea do discurso reconhecido como um tipo de perseveração motora envolvendo os mecanismos do discurso, frequentemente ocorrendo em estereotipias prosódicas, tais como índice de aceleração, pitch elevado ou volume decrescente (palilalia áfona), considerado como uma repetição involuntária de outras expressões vocais.

Do ponto de vista linguístico, a palilalia causa um desconforto prosódico para o ouvinte, uma vez que essa repetição involuntária causa um estranhamento. 
Ressaltamos que, embora a palilalia fuja aos padrões da língua, o conteúdo principal da mensagem não é afetado.

Tendo em vista a discussão realizada na presente seção, ressaltamos a importância de verificarmos a repetição na oralidade de um sujeito com palilalia com o intuito de analisar em quais situações a repetição aparece, além de perceber quais as atividades epilinguísticas são por ele utilizadas. Adiante, expomos a metodologia aplicada nesse trabalho e, em seguida, as análises dos dados.

\section{Metodologia}

Para o trabalho que, por ora, desenvolvemos, fazemos uso dos pressupostos teórico-metodológicos da Neurolinguística Discursiva. Este se baseia num estudo de caso por meio de sessões realizadas longitudinalmente e semanalmente com o sujeito MM. Para este estudo, alternamos atividades ora em grupo, ora individual, no período que se dá de abril de 2012 até dezembro de 2015 (dos 46 aos 50 anos de MM). O sujeito da pesquisa, MM, aos 45 anos e 9 meses, apresentou um episódio de ruptura de aneurisma de artéria no território cerebral médio à esquerda com uma hemorragia subracnóide, que necessitou de drenagem e cirurgia de clipagem ${ }^{9}$, apresentando como sequelas dificuldades motoras e de linguagem. Para o acompanhamento longitudinal, selecionamos atividades significativas para os interlocutores em meio a atividades discursivas e dialógicas. Dessa maneira, compreendemos MM como um sujeito que se constitui como sujeito dialógico ao produzir seu discurso e expressar a sua subjetividade e intersubjetividade por meio da oralidade. As atividades são registradas por meio de áudios que posteriormente são transcritos e analisados, fazendo uma ponte entre a teoria e os dados. Essas atividades são desenvolvidas no $\mathrm{ECOA}^{10}$ e está vinculado ao Laboratório de

\footnotetext{
${ }^{9}$ A clipagem é um procedimento cirúrgico que como o próprio nome diz consiste na colocação cirúrgica de um clip metálico entre o vaso normal e o aneurisma, excluindo-se desta forma a passagem de sangue para o interior do saco aneurismático. Este procedimento é realizado através da craniotomia, ou seja, uma pequena abertura no crânio.

${ }^{10}$ Espaço de Convivência entre afásicos e não afásicos. Este espaço é vinculado ao programa de Pós-Graduação em Linguística - PPGLin, oferecido pela Universidade Estadual do Sudoeste da Bahia - UESB, campus de Vitória da conquista, Bahia. O ECOA deve ser visto e compreendido como uma comunidade de fala tal como o CCA/ Unicamp (SAMPAIO, 2006). Pois, é composto por sujeitos que passaram por algum episódio neurológico, pelo líder/coordenador do grupo e os pesquisadores: alunos de graduação (dos cursos de Letras Vernáculas e Modernas, Pedagogia e Psicologia) e do mestrado (Linguística), sendo, também, um lugar onde se desenvolve os estudos neurolinguísticos, visando investigar, descrever e analisar o funcionamento da linguagem em cérebros-lesados que apresentam alterações na linguagem com natureza na afasia e na disartria.
} 
Pesquisa e Estudos Neurolinguísticos (LAPEN), localizado na Universidade Estadual do Sudoeste da Bahia (UESB), campus de Vitória da Conquista.

As gravações com a linguagem do sujeito MM mostram a linguagem em funcionamento nas atividades significativas das quais retiramos os dados-achados. Conforme Coudry (1996), os dados-achados são o produto da articulação de teorias sobre o objeto que o investigador se propõe investigar com a prática de avaliação e acompanhamento. Os dados são vistos como pistas que mostram ao investigador aquilo que se propõe a fazer de acordo com a teoria estudada.

\section{Análise de dados: uma amostra da repetição na linguagem de MM}

A seguir expomos um recorte do trabalho realizado com o sujeito MM. Para tanto, coletamos os dados a partir de um acompanhamento longitudinal como prática metodológica adotada para esse trabalho, como informado anteriormente. No quadro abaixo, temos um diálogo de Ima (pesquisadora/mediadora) e MM, que produz repetições.

Quadro 1. Sobre a semana ${ }^{11}$

\begin{tabular}{|c|c|c|c|}
\hline $\begin{array}{c}\text { Sigla do } \\
\text { interlocutor }\end{array}$ & Transcrição & $\begin{array}{l}\text { Observações } \\
\text { sobre as } \\
\text { condições de } \\
\text { produção } \\
\text { processos de } \\
\text { significação } \\
\text { verbais }\end{array}$ & $\begin{array}{c}\text { Observações } \\
\text { sobre as } \\
\text { condições de } \\
\text { produção } \\
\text { processos de } \\
\text { significação não- } \\
\text { verbais }\end{array}$ \\
\hline Ima & Oi::: & & \\
\hline $\mathrm{MM}$ & Oi Oi Oi & Repetição literal & \\
\hline Ima & $\begin{array}{l}\text { Boa tarde, MM. } \\
\text { Tudo bem? }\end{array}$ & & \\
\hline MM & $\begin{array}{l}\text { Tudo bem. Tudo } \\
\text { bem. Tudo bem }\end{array}$ & Repetição literal & \\
\hline Ima & Pronta pra hoje? & & \\
\hline MM & $\begin{array}{l}\text { Pronta. Pronta. } \\
\text { Acho que tô } \\
\text { pronta. Pronta pra } \\
\text { quê? }\end{array}$ & $\begin{array}{l}\text { Repetição literal e } \\
\text { modificada }\end{array}$ & \\
\hline Ima & $\begin{array}{l}\text { O que fez durante } \\
\text { a semana? }\end{array}$ & & \\
\hline MM & $\begin{array}{l}\text { Nada. Nada. Nada. } \\
\text { Nada de }\end{array}$ & $\begin{array}{l}\text { Repetições com } \\
\text { tom decrescente. }\end{array}$ & \\
\hline
\end{tabular}
As transcrições seguem, com adaptações, as normas de transcrição do Banco de Dados em
Neurolinguística do IEL/UNICAMP. 


\begin{tabular}{|c|l|l|l|}
\hline & $\begin{array}{l}\text { interessante. } \\
\text { Nada de } \\
\text { interessante }\end{array}$ & & \\
\hline Ima & Nada? & & \\
\hline
\end{tabular}

Podemos notar, no Quadro 1, evidências de repetição na fala espontânea de MM. Essas repetições ocorrem de forma irregular ao padrão que a língua propõe. Observamos que as repetições se dão de duas maneiras: literal, idêntica à palavra matriz, como por exemplo "oi, oi, oi”, e repetição modificada, com inserções, tais como "Pronta. Pronta. Acho que tô pronta. Pronta pra quê?".

As repetições nas falas de MM nos mostram que a repetição apresentada é própria da palilalia, que compreende repetições no mesmo turno. No entanto, em determinados momentos a repetição é modificada para a compreensão do ouvinte. Nas repetições modificadas, os acréscimos de palavras desenvolvidas pelo sujeito nos mostra a preocupação que ele tem de ser compreendido e de se manter na interação. A seguir, no Quadro 2, mostramos outro exemplo da repetição na linguagem de MM. Nesse quadro, temos um diálogo de MM, que produz repetições ao conversar com Ima que chega atrasada na sessão de acompanhamento.

Quadro 2. O atraso

\begin{tabular}{|c|c|c|c|}
\hline $\begin{array}{l}\text { Sigla do } \\
\text { interlocutor }\end{array}$ & Transcrição & $\begin{array}{l}\text { Observações } \\
\text { sobre as } \\
\text { condições de } \\
\text { produção } \\
\text { processos de } \\
\text { significação } \\
\text { verbais }\end{array}$ & $\begin{array}{c}\text { Observações } \\
\text { sobre as } \\
\text { condições de } \\
\text { produção } \\
\text { processos de } \\
\text { significação não- } \\
\text { verbais }\end{array}$ \\
\hline MM & Olha: chegou!! & & \\
\hline Ima & $\begin{array}{l}\text { Cheguei. Atrasada. } \\
\text { Você perdoa? }\end{array}$ & & \\
\hline MM & $\begin{array}{l}\text { Perdoa o quê? } \\
\text { Perdoa o quê? }\end{array}$ & Repetição literal & \\
\hline Ima & O meu atraso! & & \\
\hline MM & $\begin{array}{l}\text { Perdoo. Perdoo. } \\
\text { Tá perdoada. }\end{array}$ & $\begin{array}{l}\text { Repetição } \\
\text { modificada }\end{array}$ & \\
\hline Ima & $\begin{array}{l}\text { MM, você se } \\
\text { escutou? }\end{array}$ & & \\
\hline MM & $\begin{array}{l}\text { Se eu me escutei? } \\
\text { Escutei. Escutei. }\end{array}$ & Repetição literal & $\begin{array}{c}\text { Apresentando } \\
\text { dúvidas }\end{array}$ \\
\hline Ima & $\begin{array}{l}\text { Você percebeu que } \\
\text { você repetiu? }\end{array}$ & & \\
\hline MM & $\begin{array}{l}\text { Percebi. Percebi. } \\
\text { Eu me percebi }\end{array}$ & $\begin{array}{l}\text { Repetição } \\
\text { modificada }\end{array}$ & \\
\hline Ima & Não precisa, né? & & \\
\hline
\end{tabular}


O Quadro 2 nos mostra que MM produz repetição literal e repetição modificada com certa frequência. Entretanto, MM não parece percebê-las no ato de sua fala, o que demonstra que as repetições têm um valor automático. MM só percebe a repetição após ser questionada pelo investigador que permite, nesse momento, que MM reflita sobre a sua linguagem.

Ao se permitir pensar sobre a linguagem, MM desenvolve uma atividade epilinguística, pois recorre à sua fala que, mesmo repetindo, faz uma modificação na repetição ao fazer inserções, como em "Percebi. Percebi. Eu me percebi". Esse ato de pensar sobre a linguagem só é possível com a presença do investigador, ao passo que se trata de uma monitoração para que $M M$ evite as repetições, melhorando a sua linguagem.

No Quadro 3, exemplificamos uma conversa informal em que $M M$, conversando com Ima, demonstra afeto e carinho pelo esposo ao desenvolver uma atividade epilinguística.

Quadro 3: O jeito dele

\begin{tabular}{|c|c|c|c|}
\hline $\begin{array}{l}\text { Sigla do } \\
\text { interlocutor }\end{array}$ & Transcrição & $\begin{array}{l}\text { Observações } \\
\text { sobre as } \\
\text { condições de } \\
\text { produção } \\
\text { processos de } \\
\text { significação } \\
\text { verbais }\end{array}$ & $\begin{array}{c}\text { Observações } \\
\text { sobre as } \\
\text { condições de } \\
\text { produção } \\
\text { processos de } \\
\text { significação não- } \\
\text { verbais }\end{array}$ \\
\hline Ima & Ah??? & & \\
\hline MM & $\begin{array}{l}\text { É o jeito dele de } \\
\text { ser. É o jeito dele } \\
\text { de ser }\end{array}$ & & \\
\hline MM & & risos & \\
\hline Ima & Como é que é? & & $\begin{array}{l}\text { Chamando atenção } \\
\text { para as repetições. }\end{array}$ \\
\hline MM & $\begin{array}{l}\text { É o jeito dele de } \\
\text { ser }\end{array}$ & Sem repetição & \\
\hline Ima & $\begin{array}{l}\text { E como é o jeito } \\
\text { dele de ser que } \\
\text { encanta MM? }\end{array}$ & & \\
\hline MM & $\begin{array}{l}\text { Ele é todo - } \\
\text { romântico. } \\
\text { Romântico. } \\
\text { Romântico. }\end{array}$ & $\begin{array}{l}\text { Repetição de } \\
\text { palavras }\end{array}$ & \\
\hline Ima & Como é que é? & & $\begin{array}{l}\text { Chamando atenção } \\
\text { para as repetições. }\end{array}$ \\
\hline MM & Romântico. & & Sem repetição \\
\hline Ima & $\begin{array}{l}\text { É o jeito dele de } \\
\text { ser! }\end{array}$ & & \\
\hline MM & É. & & \\
\hline Ima & Todo romântico. Aí, & & \\
\hline
\end{tabular}




\begin{tabular}{|l|l|l|l|}
\hline & você gosta! & \\
\hline & RECORTE & \\
\hline MM & $\begin{array}{l}\text { É estar viva. Estar } \\
\text { na minha casa, } \\
\text { minha casa, } \\
\text { minha casa. }\end{array}$ & $\begin{array}{l}\text { Repetições de } \\
\text { palavras }\end{array}$ & \\
\hline Ima & $\begin{array}{l}\text { Na sua casa? } \\
\text { Ma sua casa, na } \\
\text { minha casa, } \\
\text { minha casa, } \\
\text { minha casa, } \\
\text { nossa casa. }\end{array}$ & $\begin{array}{l}\text { Repetições de } \\
\text { palavras }\end{array}$ & \\
\hline & RECORTE & & \\
\hline
\end{tabular}

No Quadro 3, percebemos que a repetição ocorre de muitas formas na fala de MM. No entanto, a presença do investigador promove modificação na sua fala ao chamar atenção para as repetições proferidas.

Ao considerar a repetição supracitada como algo a ser estranho para a língua, o investigador faz com que MM não faça repetições desnecessárias, como são mostradas em sua fala, ao questioná-la, "como é que é?", chamando a atenção de MM para a repetição por ela produzida. Dentro do contexto apresentado, MM entende o questionamento e produz um enunciado sem a presença de sua repetição. Dessa maneira, consideramos que o investigador, enquanto mediador, faz o papel de intermediar o sujeito e a linguagem com a finalidade de melhorar a sua desenvoltura com a fala. Nesse processo, é percebível que, entre os interlocutores, há uma negociação do discurso, como postula Coudry (2001), tornando possível uma conversação significativa.

Outro ponto importante a ser explorado em relação à linguagem de MM é a maneira como ela faz a sua correção com variação, tal como em, "Na sua casa na minha casa minha casa - nossa casa". A função repetitiva exercida por MM foi de corrigir o pronome possessivo. Ao fazer o uso de "sua", MM reproduz a fala de Ima, mas, ao se dar conta que a casa é dela, recorre para "minha"; entretanto, novamente se dá conta de que ela é casada e fala "nossa". Para chegar ao que quis expressar, MM precisou reformular sua fala por duas vezes com o propósito de manter a interação, já que MM apresenta uma preocupação com a informação que ela quer transmitir, permitindo um sentido completo.

Dito isso, percebemos que, durante a mediação e a reformulação de $M M$, foram exploradas atividades epilinguísticas que levam MM a agir com e sobre a linguagem, diminuindo o número de repetições e fazendo escolhas que ajudam o 
interlocutor a compreender as suas intenções. Dessa maneira, MM efetiva o seu papel de usuário da língua ao pensar sobre a língua e seus processos. Assim, a atividade epilinguística, conforme Coudry (2002), explicita-se ao investigador nos silêncios, nas parafasias, nas contaminações, autocorreções, mesmo expressando sua tensão e insegurança.

Além disso, verificamos que a significação apresentada por MM mostra que advém de uma série de fatores e que não é dada previamente. Assim, confirmamos a hipótese formulada por Franchi (1997), autor que serviu de base para os preceitos da ND, sobre a indeterminação da linguagem. Para o autor, nada na linguagem é dada previamente, mas é construída ao longo do processo de sua vigência com intenção apresentada pelo sujeito. Este se presta ao papel de exercer a seu favor a força criadora da linguagem.

\section{Considerações finais}

Consideramos que a repetição apresentada na linguagem de MM se trata de um problema linguístico que, por meio da mediação ${ }^{12}$ do outro, pode ser ressignificada, visto que serve de processo alternativo para a manutenção de MM nas suas interações. Neste trabalho, a repetição foi considerada em sua característica on-line, com o monitoramento do texto discursivo, como qualquer situação discursiva na oralidade, presente e profícua. No entanto, muito embora seja parte constitutiva da organização da conversação, no que diz respeito a indivíduos cujo cérebro apresenta lesões, não desconsideramos que a repetição exerce um papel diferente e singular.

De tal modo, podemos mencionar que a repetição em indivíduos cujo cérebro passou por episódio neurológico se manifesta tanto como monitoramento, em situações discursivas com a finalidade de se inserir nas práticas dialógicas, quanto como marcas da subjetividade do sujeito, permitindo, assim, que ele reflita e opere na/com a linguagem, apresentando a repetição como algo significativo dentro do discurso e contexto estabelecido, da mesma maneira que aquelas analisadas neste artigo ao longo da situação enunciativa elaborada por MM.

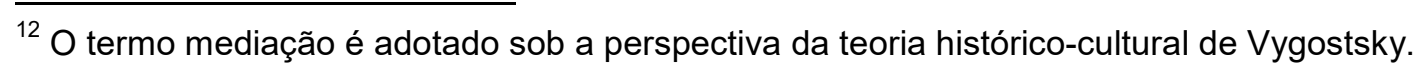


Diante disso, por este artigo ter como base a Neurolinguística Discursiva, observamos, também, que as repetições apresentadas na linguagem de MM nos mostram que, por meio do funcionamento da linguagem, a linguagem é constitutiva, pois não está pré-determinada, e se organiza ao passo que o discurso também age com essa forma criadora da linguagem.

\section{Referências}

BESSA-NETO, Regina Stella. A repetição lexical em textos narrativos orais e escritos. Dissertação (Mestrado) - Faculdade de Letras, Universidade Federal de Minas Gerais. Belo Horizonte, 1991.

CHO, Yang-Je; HAN, Sang-Don; SONG, Soul Keun; LEE, Byung In; HEO, Kyoung. Palilalia, echolalia, and echopraxia-palipraxia as ictal manifestations in a patient with left frontal lobe epilepsy. Epilepsia, v. 50, n. 6, p. 1616-1619, 2009. Disponível em: <http://dx.doi.org/10.1111/j.1528-1167.2008.01980.x>. Acesso em: 09 jun. 2017.

COUDRY,M. I. H; FREIRE, F. M. P.; ANDRADE, M. L. F.; SILVA, M.A. Caminhos da Neurolinguística Discursiva: teorização e práticas com a linguagem. Campinas, SP: Mercado de letras, 2010.

COUDRY, Maria Irma Hadley. Diário de Narciso: discurso e afasia: análise discursiva de interlocuções com afásicos. 3.ed. São Paulo: Martins Fontes, 1988. (Edição consultada: 2001).

CRITCHLEY, M. On Palilalia. Journal Neurol Psychopathol. London, p. 23-32, 1927.

FRANCHI, Carlos. Linguagem-Atividade Constitutiva. Cadernos de Estudos Linguísticos. Campinas, Unicamp, v. 22, p. 9-39, 1992. Disponível em: <https://periodicos.sbu.unicamp.br/ojs/index.php/cel/article/view/8636893/4615>.

Acesso em: 09 jun. 2017.

LANDI, Doriana et. al. Complex epileptic palilalia: A case reported. Seizure, v. 21, n. 8, p.655-657, 2012. Disponível em: <http://www.seizure-journal.com/article/S10591311(12)00155-0/fulltext>. Acesso em: 09 jun. 2017.

LEMOS, Dulce. Disartria. Rio de janeiro: Enelivros, 1992.

LIMA, Silvia Saraiva Pereira. A questão da perseveração na afasia. In: MORATO, E. M. (Org.). A semiologia das afasias: perspectivas linguísticas. São Paulo: Cortez, 2010.

MARCUSCHI, Luiz Antônio. A repetição na língua falada: formas e funções. Tese (Livredocência). Universidade Federal de Pernambuco. Recife, 1992. 
MORATO, Edwiges Maria. A semiologia das afasias: perspectivas linguísticas. São Paulo: Cortez, 2010.

RAMOS, Jânia Martins. Hipóteses para uma taxonomia das repetições no estilo falado. Dissertação (Mestrado) - Faculdade de Filosofia e Ciências Humanas, Universidade Federal de Minas Gerais. Belo Horizonte,1983.

TAGLIAFERRE, Rita de Cássia Silva. Formas e funções da repetição no contexto das afasias. Dissertação (Mestrado) - Instituto de Estudos da Linguagem, Universidade Estadual de Campinas. Campinas, São Paulo, 2008.

VISCARDIS, Janaísa Martins. O estatuto neurolinguístico do automatismo. Dissertação (Mestrado) - Instituto de Estudos da Linguagem, Universidade Estadual de Campinas. Campinas, São Paulo, 2005.

VYGOTSKY, Lev Semenovich. Pensamento e linguagem. São Paulo: Martins Fontes, 1989.

VYGOTSKY, Lev Semenovich. A formação social da mente. São Paulo: Martins Fontes, 1999. 